\title{
CORRIGENDUM
}

\section{Periadventitial angiopoietin 1 gene transfer induces angiogenesis in rabbit carotid arteries}

S Bhardwaj, H Roy, T Kärpänen, Y Hi, S Jauhiainen, M Hedman, K Alitalo and S Ylä-Herttuala Gene Therapy (2005) 12, 1290. doi:10.1038/sj.gt.3302573

Correction to: Gene Therapy (2005) 12, 388-394. doi:10.1038/sj.gt.3302426

The fourth author name was published incorrectly, the correct name is given below.

Y He

The authors would like to apologise for this mistake. 